\title{
Energy and Performance Assessment of Magnetic Water Chiller in HVAC System in Tropical Climate
}

\author{
Mr. Mayur Gohil, Mr Harshit Desai \\ (Assistant Proffesor, KJIT, Savli, Vadodara), \\ (Assistant Proffesor, CGPIT, Bardoli, Surat)
}

\begin{abstract}
Chiller system is becoming most essential part of HVAC industry. Now a day, many commercial building, public building, and manufacturing industries also incorporate chillers system in HVAC design, which accounts for large proportion (over a half of total electricity consumption) of electrical energy consumption. And therefore evaluation of its energy management opportunities should be the prioritized. The main objective of this paper is to demonstrate and standardize energy and performance assessment and improvement methodology of magnetic water chiller in tropical climate where occupancy of people working in "Shree Ramkrishna Export Pvt Ltd, Surat" is very high (5000/shift) in total cooling area $24907 \mathrm{ft}^{2}$. After removing scales and replacing expansion valve in $1250 \mathrm{~kW}$ chiller capacity water chiller and removing scales and replacing compressor in $950 \mathrm{~kW}$ capacity chiller, performance of these two chiller were improved and power consumption was reduced at difference load conditions. In $1250 \mathrm{~kW}$ chiller, reduction of power consumption was up to $7.79 \%$ per year at full load condition and in $950 \mathrm{~kW}$ chiller, reduction of power consumption was up to $6.05 \%$ per year at full load condition.
\end{abstract}

\section{Introduction}

Chiller is a more electricity power consumption part in a HVAC system so the energy audit of chiller is crucial for reduce power consumption. Now a day, many commercial buildings, public buildings, and manufacturing industries also incorporate chillers systems in HVAC design, which accounts for large proportion (over a half of total electricity consumption) of electrical energy consumption. And therefore evaluation of its energy management opportunities should be the prioritized ${ }^{[1]}$ so its thorough analysis is necessary in different conditions and establishing standard energy and performance audit system is necessary in all climates conditions.

Aim of this paper is to demonstrate and standardize energy and performance assessment and improvement of magnetic water chiller in tropical climate where occupancy of people working in "Shree Ram Krishna Export Pvt Ltd, Surat" is very high (5000/shift) in total cooling area of $24907 \mathrm{ft} 2$.

\section{Magnetic Water Chiller}

A magnetic bearing is a bearing that supports a load using magnetic levitation. Magnetic bearings support moving parts without direct contact and they are able to levitate a rotating shaft and allow relative motion with low friction and low abrasion. This concept is used in water chiller and it's called as magnetic water chiller. Major advantage of magnetic bearing is oil for lubrication is not required.

At "Shree Ramkrishna Export Pvt Ltd, Surat" there is a two magnetic type water chiller (950 kW and $1250 \mathrm{~kW}$ capacity).

\section{Performance Assessment Of Chiller}

Different performance parameters are available. Manufacturer provides performance matrix EER (Energy Efficiency Ratio) by ratio of net refrigeration capacity in $\mathrm{kW}$ by power input to compressor. The higher the EER, the more efficient the unit. Main performance parameter is ikW/TR and it is define by ratio of power input to compressor divided by tons of cooling produced. Lower ikW/TR indicates higher efficiency. COP (Co efficient of Performance) is define by ratio of EER by 3.413.

Study presents performance of two water chiller in tropical climate. Pre-audit performance condition was compared with post audit performance condition. At $92 \%, 65 \%$ and $42 \%$ load of pre-audit compared with $92 \%, 65 \%$ and $42 \%$ post audit load. Following table shows comparison of pre-audit performance and post audit performance of $950 \mathrm{~kW}$ and $1250 \mathrm{~kW}$ chiller.

Table 1: Pre-audit performance of $950 \mathrm{~kW}$ chiller

\begin{tabular}{|l|c|c|c|}
\hline Pre-audit & ikW/TR & EER & COP \\
\hline $92 \%$ load & 1.181 & 2.97 & 0.87 \\
\hline $65 \%$ load & 1.1711 & 3.002 & 0.8790 \\
\hline $42 \%$ load & 0.9043 & 3.88 & 1.13 \\
\hline
\end{tabular}


Table 2: Post audit performance of $950 \mathrm{~kW}$ chiller

\begin{tabular}{|l|c|c|c|}
\hline Post audit & ikW/TR & EER & COP \\
\hline $92 \%$ load & 1.089 & 3.22 & 0.94 \\
\hline $65 \%$ load & 1.127 & 3.117 & 0.9132 \\
\hline $42 \%$ load & 0.871 & 4.03 & 1.18 \\
\hline
\end{tabular}

Table 3: Pre-audit performance of $1250 \mathrm{~kW}$ chiller

\begin{tabular}{|l|c|c|c|}
\hline Pre-audit & ikW/TR & EER & COP \\
\hline $100 \%$ load & 0.9258 & 3.7978 & 1.11 \\
\hline $73 \%$ load & 0.9252 & 3.80 & 1.11 \\
\hline $63 \%$ load & 1.061 & 3.31 & 0.97 \\
\hline $32 \%$ load & 0.8572 & 4.10 & 1.69 \\
\hline
\end{tabular}

Table 4: Post audit performance of $1250 \mathrm{~kW}$ chiller

\begin{tabular}{|l|c|c|c|}
\hline Post-audit & ikW/TR & EER & COP \\
\hline $100 \%$ load & 0.8697 & 4.042 & 1.18 \\
\hline $73 \%$ load & 0.8818 & 3.98 & 1.16 \\
\hline $63 \%$ load & 1.0022 & 3.50 & 1.02 \\
\hline $32 \%$ load & 0.7904 & 4.44 & 1.30 \\
\hline
\end{tabular}

\section{Scale Removing}

Water scale on any heat transfer surface reduces the effectiveness of that heat transfer. This results in reduced equipment efficiency while increasing energy consumption, increasing costs and even increasing plant downtime. So energy audit of any heat transfer surface is required for energy saving.

Here, the descaler and chemical cleaning method were kept confidential by team of Manufacture Company and this work was done by four member team of Manufacture Company.

Figure 1 shows an evaporator's tube sheet in $950 \mathrm{~kW}$ chiller before scale removal. Figure 2 shows an evaporator's tube sheet in $950 \mathrm{~kW}$ chiller after scale removal. After scales were removed performance of both chiller were improved as shown in a table 3 and 4.

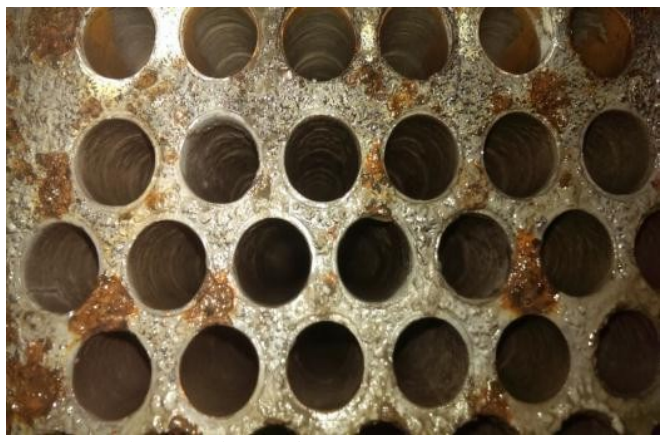

Figure 1: Before scale removal

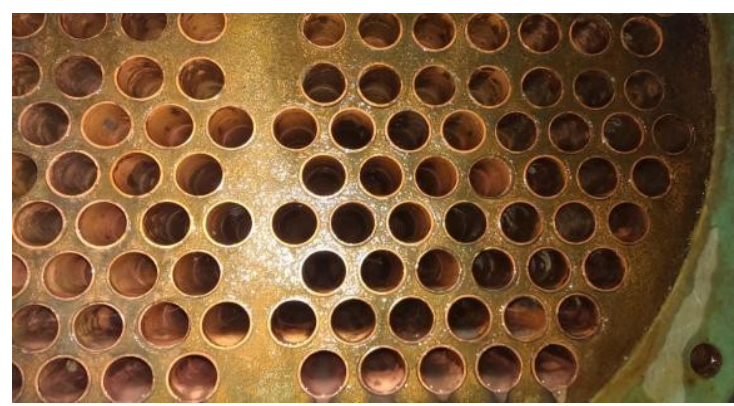

Figure 2: After scale removal

\section{Replacing Compressor}

In $950 \mathrm{~kW}$ chiller, out of three compressor, one had leakage problem. For this reason compressor was replaced. High pressure chillers using CFC-12, HFC-134a, or HCFC-22 operate at pressures well above atmospheric pressure, and leaks in these types of chiller release potentially hazardous refrigerants into the environment. Environment regulations limit the amount of annual refrigerant leaks. Leaks also results in a lower refrigerant charge and other operational problems, such as lower evaporator pressure, which can cause the compressor to work harder to produce a lower cooling capacity. 


\section{Replacing Expansion Valve}

There were two problems in electronic expansion valve in $1250 \mathrm{~kW}$ chiller (1) Controller was not working properly. (2) Noise problem. Electronic expansion valve control the flow of refrigerant entering in evaporator. They do this in response to signals sent to them by an electronic controller. A stepper motor is used to open and close the valve port. Stepper motor do not rotates continuously. They are controlled by an electronic controller. The stepper motor is driven by a gear train, which positions a pin in a port in which refrigerant flows. For this reason noise is also increased. For these two reasons expansion valve was replaced after pre-audit.

\section{Replacing Fuses}

Fuses are an important protection component of all electrical circuits. Without fuses electronic devices could be severely damaged in the event of a power surge or other event that causes excessive voltage. Fuses located after main supply were found damaged during pre-audit period. So, fuses were replaced after pre-audit.

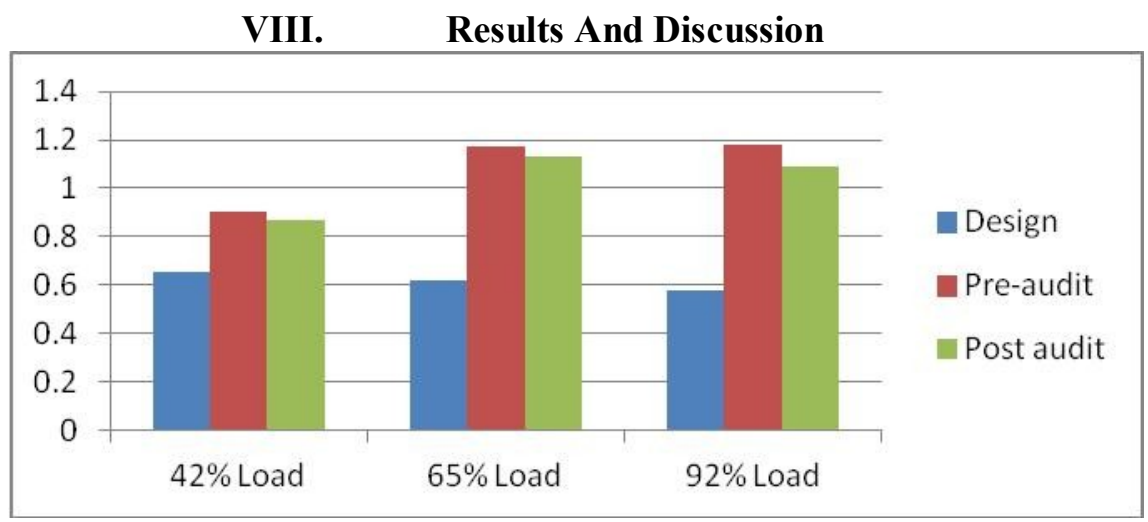

Figure 5: ikW/TR comparison for $950 \mathrm{~kW}$ chiller at $42 \%, 65 \%$ and $92 \%$ load

Figure 5 shows that power consumption of $950 \mathrm{~kW}$ chiller was reduced after removing of scaling effects by chemical cleaning method. Reduction in power consumption was mainly due to following reasons. After the removal of scale, heat transfer between hot fluid and cold refrigerant was increased, resulted in increased TR and replacement of the old compressor by new compressor of same parameters, reduction in pressure loss was noted in evaporator, which resulted in reduction of power consumption.

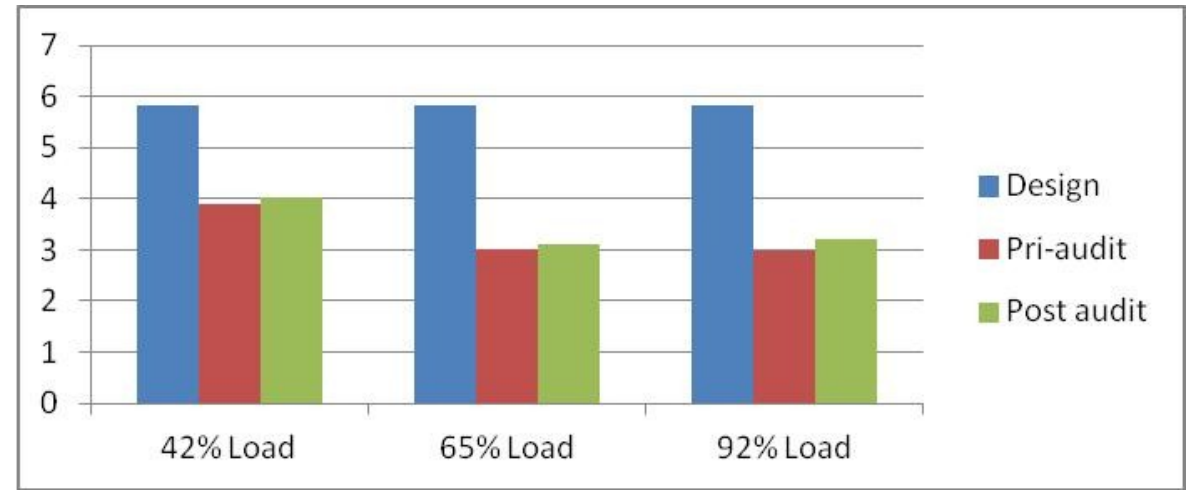

Figure 6: EER comparison for $950 \mathrm{~kW}$ chiller at $42 \%, 65 \%$ And $95 \%$ load

Above figure 2 shows that chiller performance term EER (Energy Efficiency Ratio) was increased due to descaling process and replacement of compressor.

Figure 3 depicts that due to descaling process and replacement of compressor, performance term COP (Co-efficient of Performance) was increased as heat transfer rate was increased, flow rate of water and refrigerant in evaporator also increased and decreased pressure loss in evaporator due to replacement of compressor, eventually resulted in power consumption of $950 \mathrm{~kW}$ chiller at $42 \%, 65 \%$ and $92 \%$ load. 


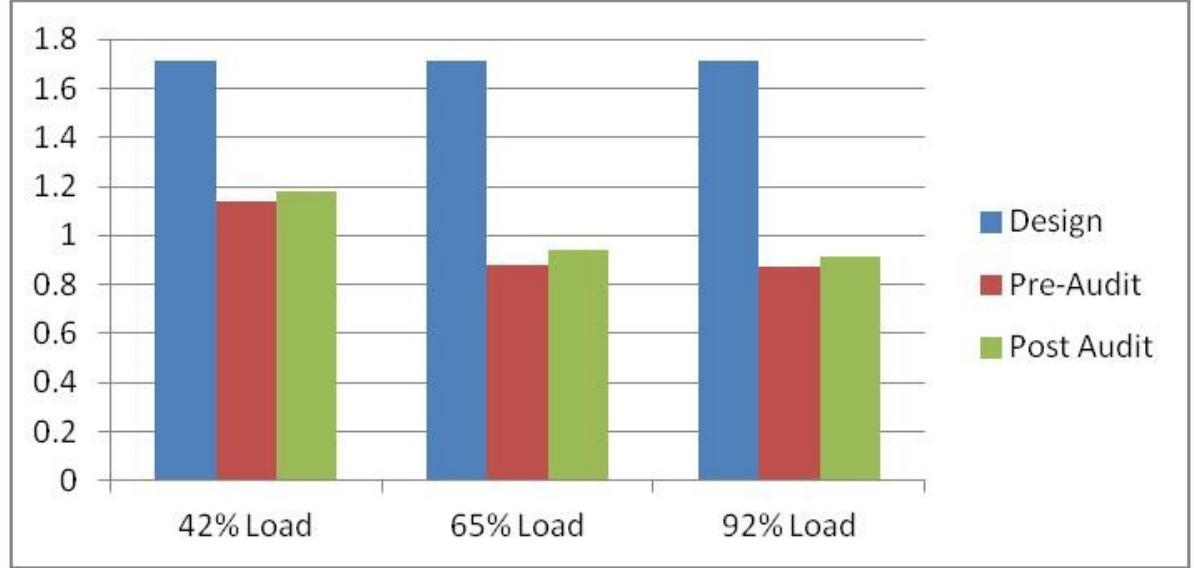

Figure 7: COP comparison for $950 \mathrm{~kW}$ chiller at $42 \%, 65 \%$ and $92 \%$ load

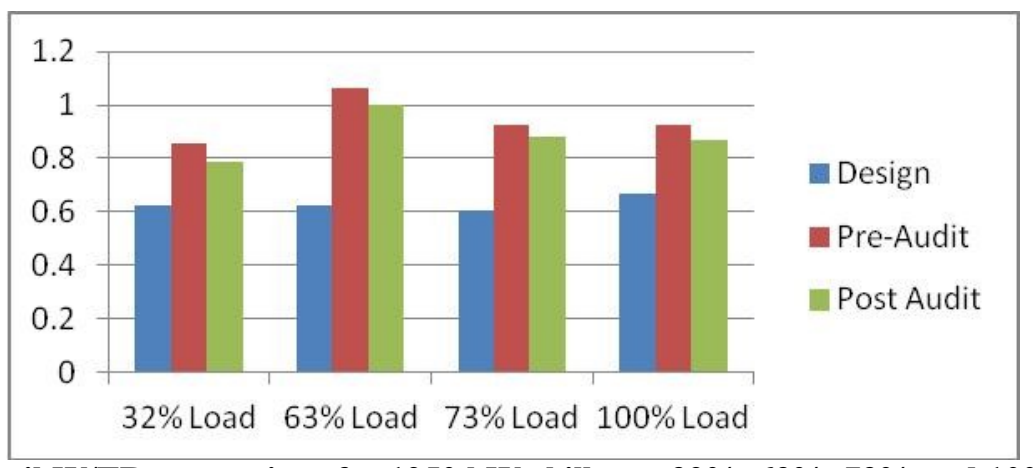

Figure 8: ikW/TR comparison for $1250 \mathrm{~kW}$ chiller at $32 \%, 63 \%, 73 \%$ and $100 \%$ load

Figure 8 shows that in $1250 \mathrm{~kW}$ chiller at $32 \%, 63 \%, 73 \%$ and $100 \%$ load power consumption by chiller were reduced after post audit due to cleaning and descaling of tubes and replacement of expansion valve. After cleaning and descaling tubes and tube sheet, heat transfer between hot water and cold refrigerant was increased and flow rate of water and refrigerant also increased. In addition to that, there was technical fault in controller of expansion valve, so flow from valve into evaporator was not sufficient as required for all the instances, so after replacing expansion valve, performance of this chiller was increased, which resulted in reduction of power consumption.

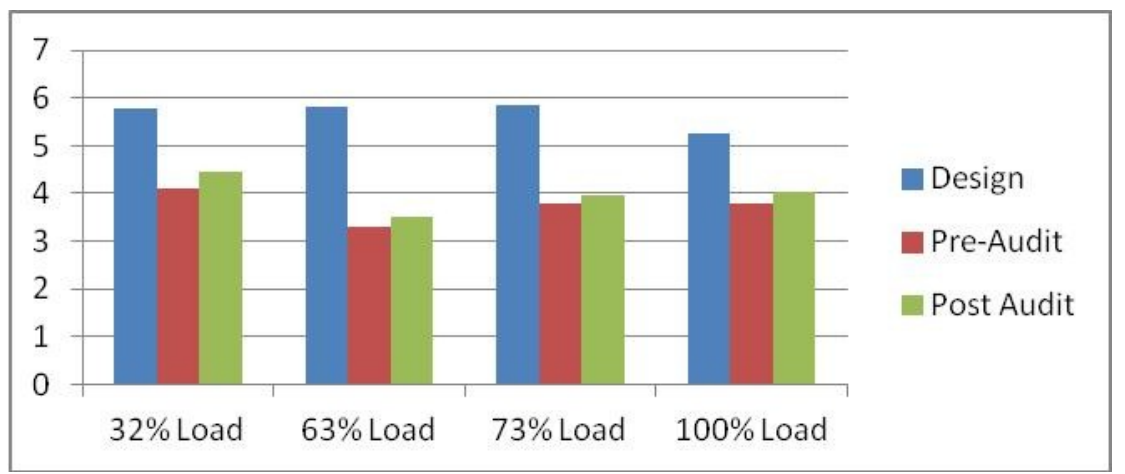

Figure 9: EER comparison for $1250 \mathrm{~kW}$ chiller at $32 \%, 63 \%, 73 \%$ and $100 \%$ load 


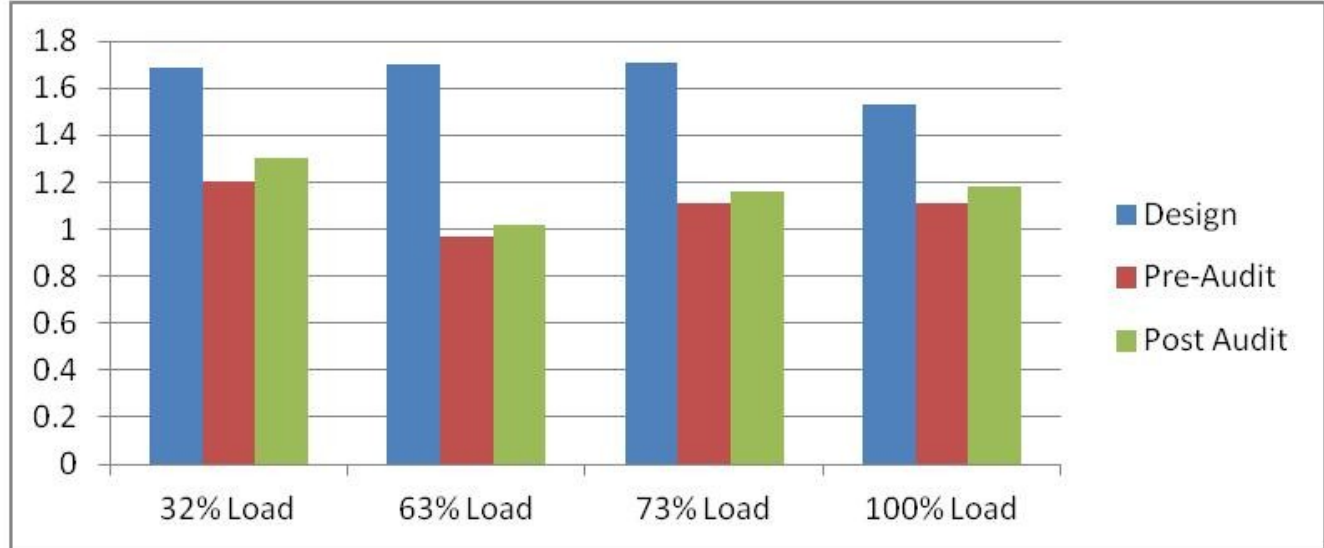

Figure 10: COP comparison for $1250 \mathrm{~kW}$ chiller at $32 \%, 63 \%, 73 \%$ and $100 \%$ load

Above figure 9 depicts that chiller performance term EER was high at post audit compared to pre-audit due to removal of scale and replacement of expansion valve.

Figure 6.6 shows that in $1250 \mathrm{~kW}$ chiller at $32 \%, 63 \%, 73 \%$ and $100 \%$ load after cleaning and descaling tubes and tube sheet and replacement of expansion valve, COP was increased, so performance of $1250 \mathrm{~kW}$ chiller at $32 \%, 63 \%, 73 \%$ and $100 \%$ load was increased.

\section{Conclusion}

Study presents energy performance assessment of two water chillers ( $950 \mathrm{~kW}$ and $1250 \mathrm{~kW}$ capacity) with magnetic bearings technology in tropical climate, where occupancy is very high (5000 person/shift) in diamond manufacturing company.

Based on energy audit data certain improvement measures were taken which resulted in successful saving of chiller energy consumption. In magnetic chiller, it is found that energy consumption is mainly reduced by removing scales in evaporator and condenser tubes and tube sheets. Other measures like replacement of compressor, expansion valve and electrical fuses may also improve heat transfer rate due to the improved temperature difference and water flow rate.

Periodic energy audit of expansion valve may result in periodic maintenance or replacement of expansion valve and timely action may reduce noise level in magnetic bearing type chillers, which will be helpful to company to match stringent government regulation regarding environment.

Periodic energy audit of compressor may result in periodic maintenance and replacement of compressor, which can prevent hazardous refrigerant to pollute the environment.

Quantification of scaling effect of heat transfer rate can be done by measuring thickness of scale formation and measuring temperature distribution along the condenser tubes and tube sheets, which has got good scope for future research. Multiphysics.

Given conditions in chiller system, can be simulated for more research in software like COMSOL

For "Shree Ramkrishna Export Pvt Ltd", Surat" methodology like multivariate analysis and design envelopment analysis can be carried out to standardize decision making in terms of flow regulation, percentage load requirement, and pumps utilization, etc.

\section{References}

[1] F.W. Yu, K.T. Chan, Improved energy management of chiller system by multivariate and data envelope analyses, Applied Energy 92 (2012) 168-174. 